\title{
Research on Management of University Public Health Emergencies----Based on 2019 New Coronavirus Events
}

\author{
Zhu Xiaoning*, Tang Yuwei

\section{Email address:} \\ Zhuxn1956@163.com (Zhu Xiaoning), 454722360@qq.com (Tang Yuwei) \\ ${ }^{*}$ Corresponding author
}

School of Public Affairs and Administration, University of Electronic Science and Technology of China, Chengdu, China

\section{To cite this article:}

Zhu Xiaoning, Tang Yuwei. Research on Management of University Public Health Emergencies----Based on 2019 New Coronavirus Events. Science Innovation. Vol. 8, No. 2, 2020, pp. 43-47. doi: 10.11648/j.si.20200802.15

Received: March 16, 2020; Accepted: May 6, 2020; Published: May 19, 2020

\begin{abstract}
As the human resource training base of the society and the national talent development center, the outbreak of the new coronavirus has brought great challenges to university management. In the face of this public health emergency, how to formulate correct emergency decision-making goals, implement scientific management behaviors, and maintain good university order reflects the comprehensive level of university management. Based on the "policy-organization-network" research framework, based on the two dimensions of "university-society" and analyzing the three main subjects of "student-staff-alumni", it can systematically sort out the relevant work of M School during the epidemic Analyze the successful experience and effective methods, and explore ways to improve the crisis management ability of colleges and universities. The study found that in the face of sudden public health incidents, policy is the direction guide for the development of universities, organization is the implementation basis of management behavior, and the network is the physical guarantee of subject contact. In addition, although scientific and effective temporary decision-making is the "quick prescription" for emergency management in universities, the organizational platform and management framework built in the long-term management process are the key to ensuring good order.
\end{abstract}

Keywords: College, Public Health Event, Crisis Management

\section{基于2019年新型冠状病毒肺炎事件的-高校突发公共卫生事件管 理研究}

祝小宁*, 唐雨薇

电子科技大学, 公共管理学院, 成都, 中国

邮箱

Zhuxn1956@163.com（祝小宁），454722360@qq.com（唐雨薇）

摘要: 作为社会的人力资源培养基地与国家的人才发展中心, 新型冠状病毒的爆发为高校管理带来极大挑战。在这一 突发公共卫生事件面前, 如何制定正确的应急决策目标、实施科学的管理行为、维持良好的高校秩序体现着高校管理 的综合水平。通过“政策-组织-网络”的研究框架, 立足“高校-社会”两个维度, 围绕“学生-职工-校友”三个主体进行分析, 能够对 $\mathrm{M}$ 学校在疫情期间的相关工作进行系统梳理, 剖析其中的成功经验与有效办法, 探寻提升高校危机管理能力的 途径。研究发现, 在突发性公共卫生事件面前, 政策是高校发展的方向指导, 组织是管理行为的实施基础, 网络是主 体联系的物理保障。此外，科学有效的临时决策虽是高校应急管理的“速效药方”，但长期管理过程中所建成的组织平 台与管理框架才是保证良好秩序的关键。 


\section{1. 引言}

据2018年全国教育事业发展统计公报显示, 全国共有 各级各类学校 51.89 万所, 各级各类学历教育在校生 2.76 亿人 [1]。作为社会的人力资源培养基地与国家的人才发展 中心, 高校的安全与稳定不仅是高校自身建设的重要基础, 也是关乎社会稳定与国家发展的关键区域。因此, 在突发 公共卫生事件前, 如何制定正确的应急决策目标、构建科 学的防控机制、推动教学活动的正常开展、实现校内学生 的有序管理, 将体现高校应对突发公共事件的危机管理水 平，检验高校管理的综合能力。

在疫情发展期间，M学校以“停课不停教，停课不停 学”为教学目标, 从政策、组织、网络三个方面开展了一 系列行之有效的防控工作。分析疫情期间 $\mathrm{M}$ 学校的相关准 备, 总结该校应对疫情的主要做法, 能够为高校危机管理 工作提供一定参考。

\section{2. 案例概述}

\section{1. 文献综述}

危机管理这一概念, 首次出现在1915年德国学者莱特 纳发表的《企业危险论》一书中[2]。格林 (Green) 认为, 危机管理的任务是尽可能控制事态，在危机事件中把损失 控制在一定的范围内, 在事态失控后要争取重新控制住 [3]。 根据危机管理所具有的长期性、权变性、公共性、心理约 束性等特征, 国内外学者提出一系列理论分析模型, 如最 基本的三阶段模型、斯蒂文·芬可的4阶段生命周期模型 [4]、罗伯特·希斯的“4 $\mathrm{R}$ ”模型[3] 与赵定涛、李蓓的五力模 型等[5]。

作为一种管理思想，危机管理理论为金融、公共服务 及教育等多个领域提供行动指南。当其立足于高校管理时, 也在应对各类公共安全、公共卫生问题时发挥着重要作用。 我国学者孟亮与张光否以 $4 \mathrm{R}$ 危机管理模式为框架, 通过对 高校主要安全问题的分析, 对高校安全防控体系进行探索 [6]; 向晋文从危机生命周期角度出发, 强调实现预防功能、 应激功能和修复功能的管理思路 [7]; 骆敏与王轶群等人通 过对网络舆情传播的研究, 提出应加强高校的网络與情危 机管理[8]; 黄妃对突发公共卫生事件性质的梳理, 希望能 够为高校突发公共卫生事件应急管理机制的建立提供建 议[9]。

根据已有研究, 可发现目前高校在应对突发公共卫生 事件时主要存在如下危机管理经验：（1）建立完善的公 共卫生危机事件预防与处理机制; （2）加强公共卫生工 作的思想教育; （3）打造公开、透明、高效的信息流通 机制。如刘桂颖在对 X高校防控诺如病毒的调查中指出, 建立完善的公共卫生危机事件处理机制是解决问题的根 源[10]。娄素在分析已有高校突发公共卫生事件类型与原 因的基础上，提出建立高校突发公共卫生事件防控机制的
具体建议[11]。这些研究从不同角度对问题进行分析, 能 为高校应对突发公共卫生事件提供一定帮助。但由于研究 材料单薄、研究角度片面、所提建议理论性较强等问题, 会在一定程度上削弱建议效果。通过系统的分析框架, 对 高校在应对突发公共卫生事件过程中的相关行为进行剖 析与梳理, 能够探寻到可供推广、科学有效的管理措施, 为高校建设提供帮助。

\section{2. 事件概述}

作为与疫情相关的最早通报, 由武汉市卫生健康委员 会医政医管处在2019年12月31日发布的《关于做好不明原 因肺炎救治工作的紧急通知》正式揭开该次新型冠状病毒

（2019-nCoV）事件的序幕。对于本次疫情的描述主要从 “政策-组织-网络”三个方面、围绕党中央策划的防控措施 进行。

\subsection{1. 政策层面}

政策层面, 通过系列文件进行防疫工作布局。

以2020年1月7日习近平总书记在中央政治局常委会 会议上对疫情防控工作所提要求为肇始, 党中央紧跟疫情 发展形式, 立足防疫工作具体环节, 通过多种形式传达疫 情防控要求, 进行疫情工作指挥。2020年1月16日, 国家 卫健委发布《新型冠状病毒感染的肺炎诊疗方案 (试行)》, 此次方案是基于对既往冠状病毒理化特性的认识, 对冠状 病毒病原学进行描述。此后, 随着对病毒认识的不断深入, 截止2020年3月2日, 国家卫健委已发布《新型冠状病毒肺 炎诊疗方案（试行第六版）》, 第七版新冠肺炎诊疗方案 也正在启动中 $[12]$ 。

2020年1月 27 日, 习近平总书记就各级党组织和广大 党员、干部要在打赢疫情防控阻击战中发挥积极作用作出 重要指示; 1月28日, 中共中央印发《关于加强党的领导、 为打赢疫情防控阻击战提供坚强政治保证的通知》, 动员 各级党委 (党组) 与广大党员, 为疫情防控工作做好思想 准备、构建责任体系、发挥人民力量[13]。

此后，中共中央、国务院对于金融、制造、公共交通、 医疗卫生等多个领域作出重要指示, 以推动疫情期间各行 业工作的正常开展。如1月30日, 国务院办公室发文, 对 疫情防控期间重点物资生产企业的复工复产和调度工作 发布紧急通知[14], 以保证疫情期间防疫物资产能产量、 产品库存的充足性; 2月23日, 中央应对新型冠状病毒感 染肺炎疫情工作领导小组印发《中央应对新型冠状病毒感 染肺炎疫情工作领导小组关于全面落实进一步保护关心 爱护医务人员若干措施的通知》, 以维护疫情期间一线医 护工作人员的权利, 为医护人员提供后备力量[15]。

\subsection{2. 组织层面}

组织层面, 成立中央应对新型冠状病毒感染肺炎疫情 工作领导小组。 
2020年1月25日中共中央政治局常务委员会召开会议, 决定成立应对疫情工作领导小组, 在中央政治局常务委员 会领导下开展工作 [16]。在党中央统一领导下, 各省市地 区纷纷成立疫情工作领导小组, 通过与相关部门的联动配 合, 构建多级疫情防控机制, 对防疫工作进行全面布局。

\subsection{3. 网络层面}

网络层面, 形成多主体聚力防控网络。

通过中央统一调控、地区内部发力、社会流动补充的 主要形式, 构建社会-组织-人员三点联系, 进行疫情期间 的疫情防控与社会管理。通过党中央统一领导, 地方政府 响应号召, 基层人员联动配合的方式, 形成完善的组织管 理网络与疫情响应机制、领导指挥体系。

各地在疫情防控过程中, 根据本地区疫情感染、物资 准备、医疗水平等具体情况, 进行本地疫情防控与管理。 防控期间, 以湖北省为中心, 根据各地区疫情实际, 形成 地区间对口支援网络。

此外，以各网络平台、第三方机构、企事业单位为中 心, 汇聚多方志愿力量, 进行资源缺口的社会流动补充, 形成社会互助网络。

在整个疫情防控期间, 各种体制机制与应急网络共同 配合、相互补充; 在全部防疫工作中, 政策、组织与网络 三方面措施补充配合，构成完整的防控工作体系。

\section{3. 案例分析}

本文通过“政策-组织-网络”的研究框架, 立足“高校社会”两个维度, 围绕“学生-职工-校友”三个主体, 对此次 $\mathrm{M}$ 学校在疫情事件中的管理措施进行分析。在研究过程中, 不仅剖析 $\mathrm{M}$ 学校在疫情应对中的自身优势, 也通过科学管 理行为的探索, 寻找具有普适性的管理经验。

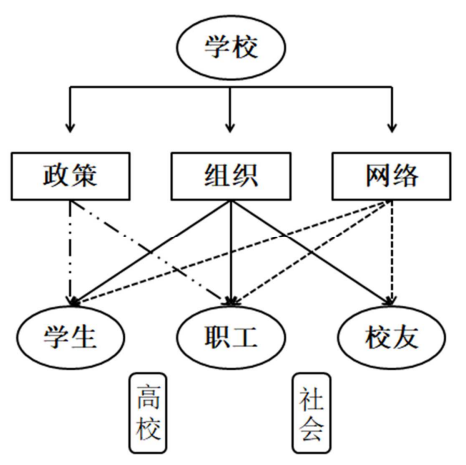

图1 案例分析框架图。

\section{1. 政策层面}

政策层面, M学校的相关决策直接作用于学生与职工 两个主体, 对校友的影响则通过政策的间接辐射产生作用。

\subsection{1. 制定防疫方案, 提供防控工作总指导}

2020年1月23日，M学校根据《中华人民共和国传染 病法》、《全国不明原因肺炎病例监测、排查和管理方案》、 《新型冠状病毒感染的肺炎诊疗方案（试行第三版）》、
《M学校艾滋病、结核病等传染性疾病防控工作方案》等 文件要求, 制定《 $\mathrm{M}$ 学校“新型冠状病毒感染的肺炎”防控 方案》。

作为 $\mathrm{M}$ 学校疫情防控的工作指南, 该方案对全校疫情 防控工作提供总指导。方案内容主要涉及工作原则、组织 机构与防控措施三个方面。值得注意的是, 在防控措施部 分, 对各项防控工作如值班值守、情况调查、通知发布等 进行相关责任主体的明确, 为相关防控工作的落实建立完 善的责任主体机制，保证防控工作效果。

\subsection{2. 发布系列通知, 推动教学工作正常展开}

疫情形势未明确前, 做好在线教学准备工作。

学校层面, 发布系列通知进行工作安排。从2月1日开 始, M学校教务处与信息中心、MPA教育中心及各学院教 务科等相互配合, 发布《关于做好 2020 年春季学期开学 阶段本科教学有关工作的通知》、《关于做好疫情防控期 间全校研究生教学组织、线上教学培训、开课测试等相关 工作的通知》等文件, 从教学组织、教学保障、教学具体 安排等多方面进行教学工作准备。

编写具体工作指南, 指导教师做好工作准备。教务处 编写《 $\mathrm{M}$ 学校新冠肺炎疫情防控期间本科教学工作指南 (教师版) 》, 从开学时间、线上教学安排及要求、线上 教学平台、专业实习、毕业设计等多个方面对本科教学工 作进行明确安排。

学院层面, 结合学院实际情况, 制定教学方案。以X 学院为例, 该学院在 2 月 4 日发布《 $x$ 学院 2020 年春季学 期前三周在线教学实施方案》, 从可选在线教学授课方式、 工作执行节点与注意事项三个方面进行教学安排。

疫情形势确定后, 明确教学目标, 安排具体任务。

学校层面, $\mathrm{M}$ 学校疫情工作领导小组发布《 $\mathrm{M}$ 学校 2020 年春季学期疫情防控期间教学工作方案》, 方案以 “按时开课、保证教学质量与教学要求、培养主动学习习 惯与学习能力”为总要求, 从教学、组织、准备三方面入 手, 进行具体内容的规定, 同时明确各级主体责任, 以确 保责任到人，保证工作效果。

学院层面, 各学院结合在线教学开展实际, 组织课程 模拟测试、课程调查、课程培训等工作活动。以 X学院为 例, 在线教学准备期间, 学院教务科发布《关于师生做好 进行线上教学开课模拟测试的通知》等文件, 进行学院内 教学工作指导。

\section{2. 组织层面}

\subsection{1. 以原有组织为基础, 进行防疫专项工作统筹}

疫情发生后, $\mathrm{M}$ 学校高度重视, 在原有组织机构即学 校卫生工作领导小组的基础上, 开展新型冠状病毒的专项 防控工作。

近年来, $\mathrm{M}$ 学校高度重视校内师生健康, 在属地卫生 部门的专业指导下, M学校成立学校卫生工作领导小组。 小组由校党委书记和校长担任组长, 实行“一把手”负责制。 通过设置校园健康教育宣传周活动、召开传染病防治学术 论坛以及开展卫生工作总结会等形式, 小组与校内相关部 
门、各学院共同配合, 致力在校内构建纵向加横向的网格 型防控体系，建立防范卫生风险的长效机制。

疫情发生后, 学校卫生工作领导小组反应迅速, 结合 相关文件制定防控方案, 确定防控工作具体内容, 并在防 控方案内落实全校各部门、学院防控责任, 为校内疫情防 控打下良好基础。

\subsection{2. 部门各司其职, 落实相关防控工作}

疫情防控全过程中, 学校内各司其职, 与其他部门、 学院加强工作联系、相互配合, 共同构建疫情防控工作体 系。

其中, 以教务处、信息中心、党委保卫部、合作发展 部为代表的四个部门分别对教学事务、技术支持、安全保

障、物资支援工作进行落实安排。

教务处: 明确各阶段教学任务, 实现教学目标。

根据不同时期具体情况, 教务处做好相应教学工作准 备。除发布系列指导性通知文件外, 教务处还通过构建学 院工作小组、建立领导小组与督导队伍三个方面开展工作。

以教学对象为单位, 构建工作小组。以本科、学术型 硕士与专业型硕士为划分标准, 在学院内建立不同工作小 组。小组内部使用微信、 $\mathrm{QQ}$ 等通讯平台进行沟通, 除基 本工作安排外, 也通过线上授课经验分享、相关信息交流 等形式, 帮助学院教师顺利授课。

建立领导小组, 发挥带头作用。根据各学院教师队伍 情况, 进行领导小组队伍组建, 发挥学院内教学工作带头 作用。领导小组建立后, 组内成员将率先进行在线教学信 息的学习与收集, 组织会议进行学院内教学实施方案讨论, 根据具体教学情况调整教学计划。

建立督导小组, 保证在线教学质量。在线课程正式上 线前, 已由学院教务科组织完成对课程督导的计划制定, 以保证课程督导任务的落实到位。此外, 也根据课程开展 的具体情况, 进行相关的教学经验分享与课程调整。

信息中心: 搭建校园信息平台, 推动教学顺利展开。

信息中心的职责为校园网络的建设管理、信息系统的 建设维护与教育技术的研究应用。疫情期间, 信息中心为 线上教学的顺利展开提供技术支持, 沟通平台搭建、在线 教学培训与技术支持是信息中心在疫情期间的主要工作。

中心所搭建的平台不仅服务于校内的全体师生, 也与 学习平台如爱课堂、中国MOOC、雨课堂等有所合作。在 线教学实行以前, 学校便以信息中心为桥梁, 通过教师负 责课程讲解, 中心提供技术支持的形式在中国MOOC等平 台建设了一批线上课程。

疫情期间, 为使教学工作正常开展, 信息中心牵头与 多个平台达成合作，通过师生账号设置、课程信息同步等 方式, 避免了师生重新注册账号、自行注册与加入课程的 繁琐, 为教师开展在线教学提供多种渠道。

此外, 信息中心以教育技术群为窗口, 在群内进行 在线课程的技术培训与问题咨询, 制作、提供多个平台 的使用手册与操作方法, 为线上教学的顺利开展提供技 术保证。

保卫部：做好校园安全保障，构筑坚实防疫壁垒。

疫情爆发时正值寒假期间，除留守值班的工作人员外， 还有部分留校学生在校生活。保卫处工作人员根据疫情发
展、校内形势等情况, 于 2020 年1月28日发布《关于加强 校门管理的通知》, 对校园疫情防控做出正式部署。其中, 严格的校门管控制度为校园安全构筑坚实壁垒。

人员分类。保卫处将进校人员分为轮班办公进校教工、 特殊情况进校教工、其他进校上班人员与因公特别校外访 客四类，不同类别人员对应不同管控办法。

严格审核。各类人员无自由进校权力, 在进校时, 需 根据工作性质与人员类别进行相应的审核和安全检查。除 相同的进校安全检查外, 轮班办公进校教工需由本部门提 前提交在校办公人员名单, 特殊情况进校教工需提前向保 卫处申请并经由单位主要负责人审批与人力资源部审核, 其他进校上班人员与因公特别校外访客需在提供自身信 息的基础上, 经由单位主要负责人、学校防疫指挥部、保 卫处等单位审核。

合作发展部: 团结广大校友群体, 凝聚全国防控力量。

以合作发展部为中心, $\mathrm{M}$ 学校校友总会为窗口, 校友 个人、企业、地区与行业校友会为单位, 团结号召广大的 校友群体, 凝聚全国甚至全球的校友力量, 为国家与学校 疫情防控提供支援。

物资支援方面。通过校友网站与微信公众号, 合作发 展部发布疫情防控物资倡议书, 号召海内外校友和社会人 士为全国各地与 $\mathrm{M}$ 学校作提供帮助。此后, 多个校友企业、 地区校友会、行业校友会为武汉一线人员、 $M$ 学校提供医 疗物资支援。

技术支持方面。在疫情防控中, 各位校友、各个校友 企业各展所长, 为全国与 $\mathrm{M}$ 学校的疫情防控提供基站建设 与电力支持、通讯建设与网络保障、数据管理与测量、基 础办公保障、信息咨询、消毒灭菌等多方面工作的支持与 助力。

\section{3. 网络层面}

工作与信息网络的搭建, 是促进 $\mathrm{M}$ 学校信息资源流通、 推动防控工作分派落实的有效工具。值得注意的是, 疫情 防控过程中所使用的工作与信息网络, 是在学校日常工作 中建成且经过长期使用, 根据经验反馈而进行程序调整与 改进后的科学成果, 而并非疫情期间紧急搭建的产物, 因 此该网络才能在特殊时期发挥良好作用。

\subsection{1. “一纵两横”的工作机制}

在学校的建设过程中, $\mathrm{M}$ 学校建成“一纵两横”的工作 机制, 搭建完善的校内工作网络。其中, “一纵”指以学校 -学院-教师团队为代表的纵向网络, “两横”指学院与学院、 部门与部门之间的横向网络。

在工作过程中, 学院团队与相关部门利用学校信息门 户网站、人事工作软件等为平台, 通过多种联系方式如微 信、QQ等作为补充, 建立起全面立体的联系网络, 有利于 学校内各学院、各团队与各机关部门之间的工作交流与沟 通。

不同高校在发展过程中将会根据具体情况建成不同 形态的工作机制, 但一个科学完善的工作机制是校内工作 有效开展的基础, 其在面对突发性校园事件时将会发挥重 要作用。 


\subsection{2. 先进的技术与信息平台}

利用本校的通信与技术优势, $\mathrm{M}$ 学校构建出先进的技 术与信息平台, 以支撑日常教学办公事务。

在信息发布方面, 已有信息发布平台包括五种形式, 分别为: 学校 (学院) 官方网站、短信平台、邮件系统 (教 师系统与学生系统）、网上服务大厅与企业微信。视频会 议平台目前包括welink与企业微信两种形式。在日常的信 息交流过程中, 各院各部门也会根据具体情况, 使用微信、 $\mathrm{QQ}$ 等方式进行信息发布。

技术与信息平台是有效交流沟通的工具, 其能够保证 信息在正常时期与紧急时期的传递与输送, 推动事件的有 效处理。

\subsection{3. 完善的主体联系网络}

联系网络中不仅包含学校各部门工作人员、各学院在 校师生等行为主体, 还包括在校生家长、校友个人与校友 企业、相关教育部门与政府机构、其他高校等行为主体。 除各学院因工作要求和社会关系所构成的联系网络外, $\mathrm{M}$ 学校以该校合作发展部、国际合作与交流处等部门为主要 窗口, 通过全球范围校友会的建立, 构建出完善的校友网 络, 通过多种活动、项目的开展构建完善的联系网络。

联系网络的搭建将加强 $\mathrm{M}$ 学校与各行为主体联络, 促 进校内外各类资源的流通。作为一个网络节点, $\mathrm{M}$ 学校在 特殊时期也能够作为信息发布的平台与窗口, 汇聚多方力 量, 提供支持与帮助。

\section{4. 结论}

对高校来说, 应对新冠状病毒这类突发性公共卫生事 件既是一种挑战, 也是一种机遇。打破原有教学秩序, 依 靠线上教学与新型管理模式进行高校管理是一种挑战; 通 过多平台多方式的选择, 全面实现线上教学, 积累线上教 学经验是一种机遇。

回顾M学校在疫情应对中的措施, 可以发现: 在突发 性公共卫生事件面前, 政策是高校发展的方向指导, 组织 是管理行为的实施基础, 网络是主体联系的物理保障, 上 述三者共同构成一个完整的组织行为框架。

值得注意的是, 政策的科学制定需结合多方面进行考 虑, 对社会环境的发展与学校具体实际的思考缺一不可; 负责事件处理的相关组织既可以是临时成立的, 但已有相 关组织基础的高校在实施管理措施时将更具效率与科学 性; 网络的搭建绝非一日之功, 在学校建设的过程中, 即 应考虑工作网络、联系网络的搭建, 以保证特殊时期各主 体间的正常交流与沟通。因此, 科学有效的临时决策虽是 高校应急管理的“速效药方”，但长期管理过程中所建成的 组织平台与管理框架才是保证良好秩序的关键。

\section{参考文献}

[1] 中华人民共和国教育部. 2018年全国教育事业发展统计公 报[R].2019。

[2] 邓元宏,杜恩龙.危机管理视角下我国出版经纪人的发展前 景 [J].出版科学,2016,24(05):34-37。

[3] 危机管理[M]. 中信出版社, (美)罗伯特·希斯(RobertHeath) 著, 2004。

[4] STEVEN F. Crisis management: planning for the inevitable [M]. Lincoln, NE: iuniverse, 1986。

[5] 赵定涛,李蓓.企业危机管理五力模型分析 [J].科技进步与对 策,2005(04):126-127。

[6] 孟亮,张光否. 基于4R危机管理理论的高校安全防控体系构 建 $[\mathrm{J}]$.现代大学教育,2017(04):91-96+113。

[7] 向晋文.危机管理视域下高校突发事件管理探析[J].高教探 索,2017(03):30-34+40。

[8] 骆敏,王轶群,伍婵提.高校网络與情的传播阶段及危机管理 机制[J].青年记者,2019(03):46-47。

[9] 黄妃.高校突发公共卫生事件应急管理探析 [J]. 现代交 际,2019(11):155-157。

[10] 刘桂颖.高校应对公共卫生事件的反思——X高校防控诺 如病毒为例 [J].现代商贸工业,2019,40(32):148-150。

[11] 娄素.高校突发公共卫生事件防控机制建立分析[J].科教导 刊(中旬刊),2018(10):10-11。

[12] 王清以.国家卫健委: 正在启动第七版新冠肺炎诊疗方案 [N]. 新京报,2020-02-29

[13] 张芯芯.中共中央印发《关于加强党的领导、为打赢疫情防 控阻击战提供坚强政治保证的通知》[N].新华网,2020-01-28

[14] 国务院办公厅.国务院办公厅关于组织做好疫情防控重点 物资生产企业复工复产和调度安排工作的紧急通知 [EB/OL].http://www.gov.cn/zhengce/content/2020-01/30/cont ent 5473087.htm,2020-01-30。

[15] 中央应对新型冠状病毒感染肺炎疫情工作领导小组.中央 应对新型冠状病毒感染肺炎疫情工作 领导小组关于全面 落实进一步保护关心爱护医务人员若干措施的通知 [EB/OL].http://www.gov.cn/zhengce/content/2020-02/23/cont ent_5482345.htm,2020-02-23。

[16] 卓越. 党中央成立应对疫情工作领导小组 [N]. 新华 社,2020-01-25。 